\title{
The Spirit of the Trail: Culture, Popularity and Prize Money in Ultramarathoning
}

\author{
Gary C. David, Nick Lehecka
}

ltramarathon running, which involves covering distances of beyond the 26.2 miles of a traditional marathon, has undergone tremendous growth within the last decade. Starting as a relatively fringe activity, ultrarunning (especially on trails and in remote locations) is becoming more mainstream as participation rates grow and the number of races increase. This growth also is reflected in the increasing commercialization of ultramarathon running, as witnessed in the sales of books, gear related to ultrarunning, and nutritional products meant to fuel ultra-distance efforts.

With growth comes change, and ultrarunning is at a crossroads regarding what it is, wants to be, and fears it will become. Prize money was formerly nonexistent in ultrarunning, a fact still reflected in some of its biggest races. The Grand Slam of Ultrarunning, comprised of competing in the Western States Endurance Run 100, Vermont 100, Leadville 100, and Wasatch 100, has no prize money for top finishers. At the same time, prize money is beginning to seep into the sport through some high profile races, an event that is causing some level of consternation regarding what it means for ultra direction and development. Larger fields can create more anonymity among its participants, where people do not know one other and field size can interfere with building familiarity. Corporate sponsors are challenging the original grassroots nature of the activity as well. Finally, increasing cost of marquee races, and the challenge of entry brought on by greater participation, is resulting in questions of whether race directors are just into it "for the money." This has created concern among some long-time participants that ultrarunning is undergoing permanent transformation brought on by increased population and commercialization.

This raises the question of, "What is the culture of ultramarathon running?", or as we call it the spirit of the trail. Not much has been done to understand and identify the culture of ultramarathoning. "Little is known about the individuals who voluntarily choose to undertake an endeavor as challenging as running $161 \mathrm{~km}[100$ miles]" (Hoffman and Fogard 2012:60). This paper explores this topic of ultramarathon culture through a broader demographic analysis, attitudinal questions, and questions about training and identity. The results yield an interesting view into the contemporary ultrarunner community, their training and racing habits, and their general attitudes about their sport and themselves. Finally, it explores the impact of the growing commercialization of ultrarunning on the community, its culture, and ultra identity.

\section{The Growth of Ultra Running}

No single governing authority exists that has defined what distance a course must cover in order for it to be classified as an 'ultra.' At its simplest, an ultramarathon is any race that covers beyond the standard marathon distance of 26.2 miles (or $42.2 \mathrm{kms}$ ). In theory, then, a race of 27 miles could be defined as an ultra, but typically is not, revealing more to the notion of what constitutes an ultra. As ultramarathon writer (and runner) John Morelock (2013:2) notes, there are "purists who insist an ultramarathon is at least 50 miles ( $\approx 80$ kilometers)." The Western States Endurance Run is thought of as the first 100 mile race, when in 1974 Gordy Ainsleigh completed an event that was originally for horses and riders.[1] Some ultra events are defined by time (6 hours, 24 hours, and more), while others involve great distances. This can include crossing the United States, or even repeated circuits around one city 
block in Queens, NY as with the Self-Transcendence Race which involves covering 3100 miles (5649 laps) over 52 days. More conventionally, over 31.1 miles (or $50 \mathrm{kms}$ ) is the general course distance required.

However, it can be a bit of an oversimplification to think about ultrarunning solely in terms of distance. More generally, the notion of traversing and/or navigating terrain and distance that goes beyond the more typical course distance and types, thus requiring greater effort than what might be associated with those more routine (road) running experiences. In this way, the ultrarunner often is looking for an experience that extends past mainstream running experiences. Primarily the competition can turn more inward. "During foot races over distances longer than the traditional marathon length, the experience of competing with one's self, the weather or the distance surpasses the experience of competing against the opponents" (Nowak 2010:37). Ultimately your chief rival is the voice in your head telling you that you cannot finish, cannot cover the distance, and in fact should not even try.

Distance running (and running in general) has undergone numerous running "booms" over the last 50 years. Agger (2010) notes the first running revolution starting in the 1960s to 1970s, spearheaded partly by the 'jogging' model provided by elite coach Arthur Lydiard and University of Oregon coach Bill Bowerman, as well as the performance of Frank Shorter in the 1972 Munich Olympic Marathon. This blossomed through the 1980s second running boom with large increases in marathon participation. (Chase 2008). Today, Agger identifies a second running revolution, which includes cross training and triathlons. Thus running may not be an end in and of itself, but a component of a larger complex of physical activity. A recent study by Active.com, a major online community and resource for race registration, found that from 2008 to 2010 "there has been a 203\% increase in marathon race participation", with half marathon participation increasing by $154 \%, 10 \mathrm{k}$ events by $155 \%$, and $5 \mathrm{k}$ events by $144 \%$ (2011). In general, "more than 403,000 road marathon finishes were recorded in the USA in 2007-an increase of over 100,000 since 2000" (Graubins 2008:1).

Another part of this revolution can be seen in going longer, and doing so on the trails. The growing interesting in ultra was sparked not just by the greater participation in running, but an increased awareness in ultrarunning as an activity. A major moment in the growing popularity of ultrarunning came with the publication of two books. The first book was Ultramarathon Man: Confessions of an All-Night Runner (2005) by Dean Karnazes. The public reception of the book catapulted the author into being the face of ultrarunning. As a New York Times book review noted, "From the cover of Runner's World magazine to a spread in Time and a scheduled appearance Wednesday night on 'Late Show With David Letterman,' ultramarathoning has probably never had such exposure" (Johnson 2005:1).

The second book was Born to Run (2009) by Christopher McDougall, which not only further increased the visibility of ultrarunning but also can be said to have revolutionized the shoe industry through the introduction of the minimalist shoe movement. "Ever since Christopher McDougall's book Born to Run hit the bestseller lists in 2009, Zappos, an online shoe retailer, has struggled to keep up with demand for minimalist footwear" (The Economist 2011). The articles goes on to report that Vibram, the company that markets and sells the quasi-barefoot shoe Five Fingers, had sales jump from $\$ 470,000$ in 2006 to $\$ 50 \mathrm{~m}$ in 2010 . The book is also credited for the jump in chia seed sales (Sax 2012). Taken together, both books have contributed much to the entry of ultrarunning into the public consciousness, influencing many to participate in them, as well as influencing the products seen as necessary to participate in such events.

The popularity of ultrarunning is currently reflected through more frequent stories in mainstream media publications like The Independent (Mesure 2010), Slate.com (Palmer 2013), The Guardian (Greenwood 2012), The Telegraph (Carlyle 2011), Washington Post (Seiss 2012), the New York Times (Seminara 2013; Solomon 2013), and the Los Angeles Times (Erskine 2013). Ultraunning content was even found on the television show Jeopardy in the category "The Race is to the Strong" (November 12, 2013). "Participation in the sport has surged over the past five years; the number of those who compete has doubled. An estimated 70,000 people run ultramarathons in North America" (Palmer 2013). Hoffman, Ong and Wang (2012) found a total of 32,352 161km finishers from 1977 to 2008, with the numbers of finishers as well as events exponentially increased during that time. As they summarize, "over the past 33 years, there has been increasing participation among older runners, greater participation among women, and growth in the average number of annual finishes for each individual finisher" (Hoffman, Ong and Wang 2012:1879). This growth has continued since 2008. Ultrarunning Magazine, which chronicles and publishes race results, has indicated that "by the end of 2009, Ultrarunning had reached 36,106 individual finishers. By the end of 2010, over 46,280 individuals had ever reportedly finished an ultra marathon" (Lacroix 2012).

Evidence for this growth can be found in the number of races offered as well. "In 1996, there were 17 trail 100-milers in the United States. In 2008, there were 59, with more rumored to be in the works" (Graubins 2008:1). 
This has resulted in lottery systems, wait lists, and registering six months before a race is set to take place, outcomes that are very recent in ultrarunning. "According to the American Trail Running Association (ATRA), the number of trail races has more than tripled since 2000 (to 2012) to 2,400.... [Ultramarathon trail running has grown as much in the last four years as it did in its first 27' (Seiss 2012). Based on the number of races on the race calendar provided by ultrarunning.com, there are 882 scheduled ultras for 2013, with 87 of them being 100 milers (as of June 2013).

The result of this rise in endurance activities has created more of an "Anyone can do it" attitude, thus reinforcing the continued increase. This is perhaps ironic given that ultrarunning has long been populated by what can be considered ordinary people doing extraordinary things. By this we mean ultramarathoning has not been dominated by the professional athlete, a person whose athletic abilities allows him or her to make their living from a sport. While this is changing in contemporary ultrarunning to some extent, it continues to be the case that "Ultras are for everyday people, and they're not wired differently. What they share is a desire to push boundaries" (Greenwood 2012).

The growth of ultrarunning also can be observed in the product lines dedicated to trail running and ultrarunning, as shoe manufacturers provide multiple models aimed directly at this market. "Over the past couple of years, competitive trail running in the USA has gone from an underground community of extreme athletes to an immensely popular extreme sports venue," ranking as the sixth most popular extreme sport in the US (Burgunder 2010). The article continues, "investing in trail running and the amazing athletes that make up this sport is a great marketing strategy for any business," a sentiment shared in other analyses of the trail and ultrarunning market (Dzierzak 2009; Running Insight 2012). Thus in a relatively short span of time, ultrarunners and trail runners have gone from having few gear options to having numerous product lines and marketing campaigns targeted specifically at them.

Ultrarunning is a changing culture. The growth and transformation of ultrarunning is not a necessarily welcomed event for those who are part of the "old school" of ultrarunning, those used to smaller fields, less attention, and no concerns over prize money. These changes are resulting in an expanded community in which there is less familiarity with the person standing next to you at the starting line. Furthermore, as with societies that undergo cultural change as the result of increased immigration, there can be a challenge in maintaining the practices and ideologies that are said to define "who we are as a people." Increased size comes with increased challenges of socialization and indoctrination into how things are supposed to be done, and a shared sense of self and practice is no longer safely assumed. This can all have the effect of making the very familiar into the almost alien, turning what was known and reliable into unknown and uncertain. This paper is aimed at providing an initial exploration into the nature and culture of ultramarathon running, along with an examination of the changes being brought by increasing sponsorship, popularity and professionalization.

\section{| Methodology}

The data for this project is part of a larger ethnographic project on the culture of ultrarunning. The primary author has been participating in ultrarunning events for over year, and endurance events for over 10 years. This has involved running in ultra events (up to 50 miles), and attending three 100 mile events in the role as pacer (a person who runs with a participant to help him or her complete the event). The primary author also has been a regular participant on an ultrarunning podcast2, providing the opportunity to engage the broader ultrarunning community in a discussion of ultra culture. Additionally, the primary author has been observing interactions on an ultrarunning listserv for over a year. The second author has been involved in endurance activities primarily related to triathlons, and has trained with elite triathletes for a number of years.

The survey data collected and analyzed are part of a larger ethnographic project on the culture of ultrarunner. As part of the Bentley UltraRunning Project (BURP3), the Bentley UltraRunning Project Survey (or BURPS) is one of the first attempts to initiate a broad-scale data collection of those who self-describe and identify as ultrarunners. The survey was developed with three goals in mind. First, the researchers wanted to gather demographic information on ultrarunners as a population. Second, the researchers were looking to identify racing and training habits of this community. This included past athletic event participation, race frequency, structured nature of training (or lack thereof), and past ultrarunning experience. Third, the researchers were trying to identify ultrarunning attitudes toward ultra events, the level of competition and camaraderie within the race fields, and the level of self-perceived uniqueness as compared to other types of runners (e.g. road marathoners, triathletes, shorter distance participants).

The survey questions were generated from a variety of sources. Along with standard demographic questions, 
survey content was derived through the authors' collective experiences as endurance athletes (marathons and longdistance triathlons), exposure to the running industry, networks within the ultrarunning community, mainstream books and magazine by and about ultrarunners, and social media sources (e.g. podcasts, discussion lists). After a draft of the survey was completed, it was shared with individuals in the ultrarunning community who are engaged in covering and participating in ultras at elite levels. Finally, the survey was pilot tested through a New Englandbased trail running club whose membership exceeds two thousand persons. A pilot of 18 was conducted (based on volunteers), who provided feedback about the questions and their experience in taking the survey.

The survey was submitted to and approved by the Bentley University Institutional Review Board. All participation was anonymous and responses confidential. The front page of the survey provided information on the purposes of the survey and how responses were to be used. All participation was voluntary, and respondents had the option to skip over questions that they did not want to answer for whatever reason.

The survey was 'live' for two months from February 19 to April 16, 2013, using Qualitrics online survey application. The survey was advertised through a variety of ultrarunning websites, listservs, podcasts, elite runner blogs, and other social media outlets. Over 882 persons opened the link to the survey. Total responses varied between questions, with a high of over 700 responses for the demographic questions at the beginning of the survey to a low of 439 responses for a question on what personal mantra(s) do you use while ultrarunning. In total, 525 respondents completed the entire survey, meaning that these persons went through all the survey pages presented online. Respondents were primarily from the United States $(87 \%)$. However the data provided here is from the entire sample of respondents.

\section{Who Runs Ultras?}

Research on ultrarunning has focused more on physical impacts (Murray and Costa, 2012; Kim et al 2012), with little attention paid to the demographics of ultrarunners (Hoffman and Wegelin 2009). Additional research has been done on the self-perception and cultural construction of the ultrarunner (Hanold 2010; Chase 2008; Tulle 2008), as well as more recently their exercise habits (Hoffman and Krishnan 2013). In terms of demographics, past studies generally have not delved beyond age, gender, education and marital status (see Hoffman and Wegelin 2010; Hoffman and Fogard 2012). Their findings indicated participants that had a mean age of 44.1 years ( \pm 9.7 years), an education level of 5.3 years beyond high school ( \pm 2.9 years), 70.1\% married, and predominantly male. The results from the BURP survey confirmed these results, indicating that the respondents for the survey were representative based on past findings.

Additionally, we explored other demographic attributes, which yielded interesting findings. Primary among them was the lack of racial diversity in survey respondents, as indicated in Table 1.

Table 1. Self-Reported Racial Classification of Survey Respondents

\begin{tabular}{|l|c|c|}
\hline Racial Classification & Respondents & Percentage \\
\hline White/Caucasion & 675 & $90 \%$ \\
\hline African American & 1 & $0 \%$ \\
\hline Hispanic & 26 & $3 \%$ \\
\hline Asian & 17 & $2 \%$ \\
\hline Native American & 4 & $1 \%$ \\
\hline Pacific Highlander & 4 & $1 \%$ \\
\hline Other & 19 & $3 \%$ \\
\hline & 746 & $100 \%$ \\
\hline
\end{tabular}

Discussions with persons within the ultrarunning community (as participants, elite runners, and race promoters) do indicate that this is reflective of ultrarunning participation, anecdotal evidence and experience through participant/ observation data collection supports this finding. In short, people who can be identified and self-identify as 'Black' 
do not participant in ultrarunning to any great extent. Additionally, they do not participant in distance running in numbers that are close to other racial groups. In fact, the organization National Black Marathoner Association (NBMA) has tried to directly address this disparity by encouraging distance running participation among Black Americans. It should be noted that some of the "Other" responses included 'mixed race' self-identification, which was predominantly a mixture of "Asian" and "Hispanic" with "White," and would not further add to the number of African-Americans. Despite this, it is a pretty stark indication that ultrarunning is a predominantly White activity.

Another demographic point generated by the BURP survey was self-report annual personal income. Figure 1 indicates that income distribution of survey respondents to the 2010 U.S. earning data. The figure demonstrates that on the whole survey respondents earned more than the U.S. population. It is difficult to make judgments about what the purchasing power of respondents, but it does show that ultrarunners do tend to come from relatively more stable financial situations in terms of income.

Finally, survey respondents, as with the demographics of ultrarunning participants skewed heavily male. $73 \%$ of respondents were male, and $27 \%$ female. As a point of comparison, we examined 2012 race results (realendurance. com) from a select number of prominent 100 mile races representing different US regions. From this, we can see that to varying degrees ultrarunning is a predominantly male activity.

Table 2. Percentage of Men and Women in Select 100 mile races (2012)

\begin{tabular}{|l|c|c|c|}
\hline Race Name & Total Runners & Male Participants & Female Participants \\
\hline Western States 100 (CA) & 381 & $312(82 \%)$ & $69(18 \%)$ \\
\hline Leadville 100 (CO) & 795 & $658(83 \%)$ & $137(17 \%)$ \\
\hline Vermont 100 & 306 & $239(78 \%)$ & $67(22 \%)$ \\
\hline Rocky Racoon 100 (TX) & 229 & $167(73 \%)$ & $62(27 \%)$ \\
\hline Umstead 100 (NC) & 150 & $96(64 \%)$ & $54(36 \%)$ \\
\hline
\end{tabular}

Thus we arrive at a general composite of the ultrarunner being a predominantly male, with a higher than average income, in their 40s, married, and white. Of course, this is just a snapshot, as ultrarunning popularity and participation continues to increase. Furthermore, while these demographics provide some sense of the types of demographics involved in the sport, it does not get to the attitudes, behaviors and habits of those who run ultras. In the next section, we explore these elements through attitudinal and other questions asked on the survey.

\section{Competition and Cameraderie in Ultra}

In order to gauge attitudes toward various aspects of ultrarunning, we asked forty-four six-point Likert-styled questions (Strongly Disagree=1, Strongly Agree=6). We used a six-point scale in order to remove a neutral option from the responses, forcing respondents who answered the question to indicate the extent to which they either agreed or disagreed with the provided statement. The order of questions was randomized through the survey software program. We also modified the wording of questions so that a respondent would not be more likely to agree to disagree with all the forty-four statements.

For the purposes of analysis, the questions were grouped into 8 categories: 1) Social Aspects; 2) Personal Transformation; 3) Personal Challenge; 4) Group Identity; 5) Pain and Suffering; 6) Nature; 7) Competition; and 8) Elite Runners. The focus of our analysis here is on those elements related to competition, camaraderie, and identity in ultrarunning culture. Nowak (2012:38) raises the point that "It is not clear whether an ultramarathon can be explicitly classified as a competitive sport event or extreme recreation." This sentiment is apparent in the survey results, and supported by the experiences of the primary author participating in ultrarunning events.

Compared to other endurance events, like marathon or Ironman, there would seem to be less of a competitive element in ultras. That does not mean there is no competition, but that competition is not necessarily the point. Responses to the following statements demonstrate this: 
Table 3. Scores for Competition Survey Questions

\begin{tabular}{|l|c|c|}
\hline & Mean Score (and n) & Standard Deviation \\
\hline $\begin{array}{l}\text { If another competitor needed water } \\
\text { during a race, I would give that person } \\
\text { mine to help them out. }\end{array}$ & $5.46(504)$ & 0.67 \\
\hline $\begin{array}{l}\text { If another competitor needed food } \\
\text { during a race, I would give that person } \\
\text { mine. }\end{array}$ & $5.15(502)$ & 0.83 \\
\hline $\begin{array}{l}\text { It is important for me to finish as high in } \\
\text { the results as possible. }\end{array}$ & $3.39(502)$ & 1.44 \\
\hline $\begin{array}{l}\text { I would give up my race to help another } \\
\text { competitor }\end{array}$ & $4.41(501)$ & 1.09 \\
\hline $\begin{array}{l}\text { I don't care where I finish as long as I } \\
\text { meet my personal goals. }\end{array}$ & $4.47(502)$ & 1.18 \\
\hline
\end{tabular}

One of the questions which yielded the most agreement was "If another competitor needed water during a race, I would give that person mine to help them out," with the mean being $5.46( \pm 0.68)$, with relatively strong agreement among respondents. We asked the same question, but about food, and the mean for that was 5.15 ( \pm 0.82$)$. This is interesting because one could rationalize that a competitor without food or water is not much of a competitor, and would be easier to beat. It would seem counterintuitive from a competition perspective. Additionally, regarding the question "I would give up my race to help another competitor," the mean response was 4.41 ( \pm 1.09$)$. Furthermore, to the question "I don't care where I finish as long as I meet my personal goals," the mean was $4.47( \pm 1.19)$, indicating some variance but still general agreeing with that statement. We might be able to then say that competitiveness per se is not an overriding factor in ultrarunning culture.

The importance of experience versus outcome can be seen in statements related to personal challenge and transformation.

Table 4. Score for Personal Challenge and Transformation Survey Questions

\begin{tabular}{|l|c|c|}
\hline & Mean Score (and n) & Standard Deviation \\
\hline $\begin{array}{l}\text { Training for and competing in an ultra } \\
\text { gives me the chance to become a better } \\
\text { person. }\end{array}$ & $4.70(504)$ & 1.06 \\
\hline $\begin{array}{l}\text { Running ultras gets me in touch with } \\
\text { who I am }\end{array}$ & $4.76(500)$ & 1.08 \\
\hline $\begin{array}{l}\text { Finishing an ultra is like finishing any } \\
\text { other kind of running event. }\end{array}$ & $2.34(503)$ & 1.19 \\
\hline $\begin{array}{l}\text { If I do not meet my race goal, then I } \\
\text { would consider the race a failure. }\end{array}$ & $2.46(504)$ & 1.08 \\
\hline $\begin{array}{l}\text { The ultrarunning experience is more } \\
\text { important than the outcome. }\end{array}$ & $4.73(504)$ & 1.07 \\
\hline $\begin{array}{l}\text { I'd rather run on a fast course than a } \\
\text { challenging course. }\end{array}$ & $2.41(504)$ & 1.06 \\
\hline $\begin{array}{l}\text { If an event is not challenging enough, it's } \\
\text { not worth doing. }\end{array}$ & $2.67(502)$ & 1.21 \\
\hline
\end{tabular}

Generally speaking, the emphasis on becoming a better person and having a unique experience that facilitates that transformation is given higher priority than outcome and meeting a personal goal. In fact, it is interesting to note that there was very strong disagreement with the statement "If I do not meet my race goal, then I would consider 
the race a failure" (mean score $2.46, \pm 1.08$ ). Obviously it would depend on what the goal was, which can go from "just finish" to finishing under a certain time goal. It is not uncommon to hear the important lessons people derived from failure, and to hear people swapping stories of failure with more frequency than stories of success. In other words, everyone who does enough ultras will have bad races, and they will likely have races where they cannot finish. This extends from the amateur to elite level. Less of a premium can be placed on speed and finishing time, even though fast times can be admired. The point here is that these elements are not given priority. What is given priority is sentiments such as "Running ultras gets me in touch with whom I am" (mean score 4.76, \pm 1.08 ).

When looking at the interactions that take place on ultrarunning social media sites, as well as those interactions during trail runs and ultramarathon events, there can be a high amount of conversation that takes place. It might seem counterintuitive to expect frequent conversation during a race, but it must be remembered that the pace at which people are moving is conversational ("conversational pace" a term that is used to describe as a way of monitoring effort) and they can be spending many hours on the trail together in relatively or extremely isolated environments. In fact, during a 2013 endurance event in which one of the authors participated, another participant said to the author at the start of the race (which took over 8 hours to complete), "If I can't talk about the (New York) Knicks, I'm running too fast."

At the same time, the social aspect of ultrarunning did not register extraordinarily high in terms of responses:

Table 5. Scores for Social Aspects of Ultrarunning Survey Questions

\begin{tabular}{|l|c|c|}
\hline & Mean Score (and n) & Standard Deviation \\
\hline $\begin{array}{l}\text { The hardest thing about not being able to } \\
\text { run is missing my training partners. }\end{array}$ & $2.65(502)$ & 1.31 \\
\hline The majority of my friends are runners & $3.40(501)$ & 1.46 \\
\hline $\begin{array}{l}\text { I run ultras for the social experience of } \\
\text { being around other ultrarunners. }\end{array}$ & $3.80(502)$ & 1.22 \\
\hline $\begin{array}{l}\text { I feel like I'm part of an ultrarunning } \\
\text { community. }\end{array}$ & $4.60(504)$ & 1.09 \\
\hline $\begin{array}{l}\text { I'd rather not talk to anyone else during } \\
\text { an ultra. }\end{array}$ & $2.33(502)$ & 1.15 \\
\hline
\end{tabular}

There was strong agreement with the statement "I feel like I'm part of an ultrarunning community" (mean score $4.60, \pm 1.09)$. Similarly, there was strong disagreement with the statement "I'd rather not talk to anyone else during an ultra" (mean score 2.33, \pm 1.15 ). There was more moderate sentiment regarding running ultras for the social experience. This might be due to the fact that the personal challenge is such a strong component. It then could be that in comparison the social element is less important, but not unimportant. This is likely the case given the importance put on being part of an ultrarunning community.

The nature of the uniqueness of the community and identity, and its importance to respondents, can be seen in the sentiments toward group identity statements:

Table 6. Scores for Ultrarunning Group Identity Survey Questions

\begin{tabular}{|l|c|c|}
\hline & Mean Score (and n) & Standard Deviation \\
\hline I am an ultrarunner & $5.10(503)$ & 1.01 \\
\hline I am a trail runner & $5.25(497)$ & 1.04 \\
\hline $\begin{array}{l}\text { The longer the distance, the more of an } \\
\text { ultrarunner you become. }\end{array}$ & $3.54(498)$ & 1.36 \\
\hline $\begin{array}{l}\text { Ultrarunners are a different breed of } \\
\text { person. }\end{array}$ & $4.58(503)$ & 1.13 \\
\hline
\end{tabular}




\begin{tabular}{|l|c|c|}
\hline $\begin{array}{l}\text { Ultrarunners are just like any other group } \\
\text { of runners. }\end{array}$ & $2.57(502)$ & 1.14 \\
\hline $\begin{array}{l}\text { Ultrarunning is more of a life-style than } \\
\text { a sport. }\end{array}$ & $4.34(502)$ & 1.19 \\
\hline $\begin{array}{l}\text { To be an ultrarunner, all one has to do is } \\
\text { complete an ultra distance event. }\end{array}$ & $3.77(499)$ & 1.30 \\
\hline
\end{tabular}

It was not surprising that people have strong agreement with the statements "I am an ultrarunner" and "I am a trail runner," again demonstrated a close alignment between the two. Likewise, there was some strong agreement with the statement "Ultrarunners are a different breed of person," a question which was asked to explore how unique ultrarunners saw themselves to be in terms of their group and personal characteristics. It starts to become clear that while anyone can potentially become an ultrarunner, just running long distances is not enough to join this group.

In fact, there was tepid agreement with the statement "To be an ultrarunner, all one has to do is complete an ultra distance event" (mean score $3.77, \pm 1.30$ ). This is a potentially important point in terms of indicating an identity which is complex. Obviously completing an ultra would qualify for the category of 'ultrarunner,' just as being able to swim might qualify a person as being one who can swim. But simply being part of the category does not automatically make one part of the group. Almost anyone can 'run' as a physical activity, even if it is just running into the other room to answer the phone. Many run for physical exercise on a casual basis over what can be considered, especially in comparison, very short distances. In fact, a person who competes in the mile on a track does necessarily run long distances (although the weekly volume might be high). There are then these additional elements which one must possess in order to be seeable as an ultrarunner. So then to the question of 'what is ultrarunning,' the overly simplistic answer is running longer than a marathon. The culture of ultrarunning, or 'the spirit of the trail,' would involve more than just completion of distance; it would involve possession of an ethos and culture that is unique to that activity.

\section{Elites}

\section{And The Role of Money in Ultra}

One of the most notable changes in ultramarathon has been the increasing presence of prize money in ultras. Major prize money has been a part of distance running for some time. Chase (2008) briefly discusses the commodification of the New York Marathon, with increased participation numbers as well as increased corporate sponsors. As Cooper (1992), Fred Lebow's takeover of the NYC Marathon resulted in the transformation of the major marathon, which "served the purposes of managerial capitalism, the 'visible hand,' which, in this case, used capital and technology to meet a demand that was as much created by road racing administrators and sponsors as determined by the market" (p.244). While elites had long been part, if not exclusively part, of long-distance events, it was the opportunity to race as professional runners that was a major change in the sport.

Today, winning a major road marathon can result in major prize money. Male and female winners of the 2013 Boston Marathon won \$150,000 each, with the New York City Marathon awarding winners \$130,000, Chicago Marathon $\$ 100,000$, and the London Marathon $\$ 55,000$. There are other time-based incentives, course record incentives, and where applicable (based on course certification) world record incentives. This also does not include appearance fees, sponsor bonuses, and other opportunities (for instance speaking engagements). Wins (or good results) would yield more in additional fees after the race and in the upcoming year's race calendar. All of this is made possible through corporate sponsorships of events, allowing for the development of packages that attract the best runners to run the fastest times. Money in marathon has gotten to the point that "marathons are luring runners from other disciplines - the 10,000 meters, cross country - to the point that those events are in decline" (Vigneron 2013).

By and large this situation does not exist in ultrarunning. In fact, it is more common to find that no prize money is offered for winning an ultramarathon. For instance, the Grand Slam of Ultrarunning involves four 100 mile races: the Western States Endurance Run, Vermont 100, Leadville 100, and Wasatch 100. No prize money is awarded for winning any of those races. In fact, there is no prize money associated with winning the Grand Slam, accomplished 
by accumulating the lowest total time running all four in one year. These are not exceptions. What's more, "[f]or many elites, the modest payoffs don't even cover travel costs to an event" (Seiss 2012). In other words, it costs more to do them than they get for winning. In conversations with elite ultrarunners, it is not uncommon for them to lose money on racing, spending more than they win or make through sponsorships. Additionally, there is very rarely any appearance fee money, and it can even be rare to have complimentary entry to an ultramarathon due to one's elite status. In fact, there are races such as the Hardrock 100 which does not give any preferential treatment to elite runners in terms of getting into the race. Elites have to enter through a lottery like all other runners. Elites may be separate based on their results, but not in their treatment.

There are of course exceptions to this. The North Face Endurance Challenge Championship (in San Francisco) offers a total prize purse of $\$ 30,000$ ( $\$ 10,000$ for first place). The Cayuga Trails $50 \mathrm{~m}$ ultra (Ithaca, NY) offered a $\$ 10,000$ prize purse $(\$ 2,500$ for first place). The Run Rabbit Run 100 (Steamboat Springs, CO) offers $\$ 10,000$ for first place. The Ultra Race of Champions (or UROC) $100 \mathrm{~km}$ race has a $\$ 20,000$ prize purse ( $\$ 5,000$ for first place), which is intended to draw the best ultrarunners to compete head to head. As the UROC website states, "The Ultra Race of Champions 'UROC' will provide additional incentives to encourage the best ultra runners in the world to compete" (ultraoc.com).

Clearly there is a difference between marathons and ultramarathons. This is magnified to a greater extent if one considers the money per mile and hour earned by winners. The winner of the Boston Marathon would earn $\$ 5,725.19$ per mile, while the winner of the Run Rabbit Run would earn $\$ 100$ per mile. The winner of the 2013 Boston Marathon for the men’s race Lelisa Desisa ran in a time of 2:10:22, making $\$ 69,036.05$ per hour (or $\$ 1,150.60$ per minute). Rob Krar won the 2013 UROC 100k in a time of 9:29:00. Being roughly 62 miles long, this earned him $\$ 80.65$ per mile. In terms of his finishing time, he earned $\$ 527.24$ per hour (or $\$ 8.79$ per minute). Jason Schlarb won the 2013 Run Rabbit Run in 17:15:20, earning him $\$ 579.60$ per hour (or $\$ 9.66$ per minute).

There are other ways for elites to make money through ultrarunning, primarily in the form of sponsorships. For elites, sponsorships might be the only way they can afford to race at all. An example of this is Mike Morton, who is one of the best American ultrarunners, and who holds the American 24 hour record of 172.45 miles. A local community paper published the story "Ultramarathon Runner ready to Defend World Championship Title, Seeks Community Support" (Mondovics 2013), in which his wife relates "We are trying to get sponsorship from local companies for Mike's upcoming races." Additionally, she states, "Mike will happily promote any business that would like to sponsor him as well as donate funds to the Special operations Warrior Foundation and Team Red, White, and Blue." Mike Morton is a Master Sergeant in the US Army, having forgone ultrarunning for 14 years during deployments and military training. The fact that such an accomplished ultrarunner, including world championship wins and being named USATF Men's Ultra Runner of the Year in 2012, is depending on local companies is interesting when compared to the compensation that other elite marathon distance runners can receive. Furthermore, it is extraordinarily rare that even sponsored athletes receive financial compensation. Rather, they are more likely to receive free products in exchange for endorsing the product, perhaps assistance in the form of race entry fee reimbursement and perhaps some race travel stipend.

This might create the appearance that more prize money should be added to ultramarathons to more adequately (or fairly) compensate the winners when compared to the winners of 'shorter' distance races like marathons. It is rarely the case that elite ultrarunners can make "a living" solely by running. Karl Meltzer, the record holder for the most $100 \mathrm{~m}$ victories, states "Am I making money running races? No. Even if you win them all, you would still only be making about $\$ 30,000$ a year" (Seiss 2012). It is of course not possible to win them all, and winning (let alone finishing) is always an open question. In fact, the vast majority of ultrarunners that can be termed 'elites' have fulltime jobs that they rely on for their livelihood. The aforementioned Rob Krar for instance is a pharmacist. In that way, elites are like the amateurs, trying to balance work, family, friends and training. This can be an important element in the identity of the ultrarunning community, and speaks to part of the more egalitarian ethos that permeates. The elites are just like us, only faster.

In the BURP survey, we asked about the presence of elites at races, and the impact elites have ultramarathons.

Table 7. Scores for Ultrarunning Group Identity Survey Questions

\begin{tabular}{|l|c|c|}
\hline & Mean Score (and n) & Standard Deviation \\
\hline $\begin{array}{l}\text { Elite runners deserve preferential treat- } \\
\text { ment for entering marque events. }\end{array}$ & $3.24(504)$ & 1.43 \\
\hline
\end{tabular}




\begin{tabular}{|l|c|c|}
\hline $\begin{array}{l}\text { More prize money is needed to help the } \\
\text { development of ultras. }\end{array}$ & $2.48(501)$ & 1.31 \\
\hline $\begin{array}{l}\text { The presence of elites should have no } \\
\text { impact on the prestige of an event. }\end{array}$ & $4.24(499)$ & 1.30 \\
\hline $\begin{array}{l}\text { The presence of elite runners makes a } \\
\text { race more exciting. }\end{array}$ & $3.80(503)$ & 1.40 \\
\hline $\begin{array}{l}\text { The more well-known professionals are } \\
\text { in the mainstream, the better it will be } \\
\text { for ultrarunning in general. }\end{array}$ & $3.38(502)$ & 1.29 \\
\hline
\end{tabular}

From the responses, we can see that attitudes did not indicate a strong preference or endorsement for the presence of elites in races. Keeping in mind that a score of " 3 " would indicate "Somewhat Disagree" and "4" "Somewhat Agree," attitudes seem to show that people only mildly agree or disagree with these statements. The highest score was for "The presences of elites should have no impact on the prestige of an event." The lowest score (and thus strongest disagreement) was for the statement "More prize money is needed to help the development of ultras." This would indicate that ultrarunners, while they admire the physical capabilities of elites, do not place a premium on their participation to define what ultrarunning is.

We asked another question of "If you are NOT an elite runner, does the presence of elite runners in the field make you more likely to want to participant in that event?" $69 \%$ of respondents (n=375) said "No", with only $28 \%$ ( $\mathrm{n}=152$ ) saying "Yes." To find out what draws runners to different events, we ask respondents to rank 16 factors in order of their importance, with a placement of first being the most importance and sixteenth being the least important. The top three reasons that a race was chosen included "Scenic nature of the course" (mean score 4.09), "Close to home" (mean score 4.14), and "Easy to travel to" (mean score 4.91). The least important of the provided factors included "Amount of prize money available" (mean score 13.61), "Part of a [sponsored] series" (mean score 12.25), and "Highly competitive field" (mean score 11.57).

Taken together, for respondents elites do not factor as an important element when choosing a race, and should not be given preferential treatment. This latter element is important given that many ultras have strict entry limitations given they are run on federal and state land, requiring permits that dictate how many can participate. Also, larger fields can have greater environmental impacts on the trails, and create greater challenges for race directors (especially over greater distances in remote areas). For example, the Hardrock Endurance Run 100 mile event is run in the San Juan Mountains, starting in Silverton, Colorado. The course record for men is 23:23:30, and for women 27:18:24. It is considered one of the most challenging and sought after races for many ultrarunners, the pinnacle of achievement due to its total elevation change of 67,984 feet and average elevation of 11,186 feet. The finishing time cut-off is 48 hours. 140 persons are allowed into the race every year. For the 2014 edition, 1133 persons applied for the race lottery, all of whom had to complete a qualifying event. Elites are given no preferential treatment for entry, and no prize money is given for first place.

In discussing what he calls "the politics of prize money," elite runner Geoff Roes writes, "One can argue for or against big prize money in ultrarunning for hours, but one thing that is undeniable is that prize money brings runners out to events." Regarding newer races that have prize money and larger fields, he continues "Not only are each of these races going to be hyper competitive at the front of the field, but they are all going to have unprecedented field sizes for the age of their races" (Roes 2012). Another elite runner Andy Jones-Wilkins divides the argument over prize money between "purists" and "pragmatists." The purists, he states, "argue that the introduction of prize money to ultramarathon running would only serve to corrupt our otherwise clean sport and could lead to such unsavory things as cheating, performance enhancing drug use, and corporate greed." The pragmatists, on the other hand, "suggest that the addition of prize money would increase competition, bring increased attention to the sport, and add an air of professionalism to a sport that has been rather loosely organized and administered for over 30 years." He asks in his article, "What happens if the ethic of the sport changes and the product outpaces the process? If that indeed happens, I'll be worried" (Jones-Wilkins 2011). His worry is shared by many ultrarunners. The calculus of more prize money leads to more elites, faster times, more attention to ultra, and a growth in the sport is not universally shared as a goal. In fact, there are many who would say this is exactly the wrong way to go, and that growth in the sport is degrading its essence. 
Perhaps nowhere was this more evident than in the 2013 Leadville 100, where the primary author was a pacer. The Leadville 100 was started as a way of stimulating the economy of Leadville, Colorado whose economy was dependent on mining. Started in 1983 with 45 runners, the "Race across the Sky" has become another pinnacle of ultrarunning. The entire Leadville Race Series (comprised of running and mountain biking events) was bought by Lifetime Fitness in 2010, a publically traded company that had revenues in 2010 of $\$ 912.8$ million who self-describes that it "helps organizations, communities and individuals achieve their total health objectives, athletic aspirations and fitness goals" (lifetimefitness.com). According to the website realendurance.com, the race enjoyed a gradual increase during the time of its existence, with more substantial increase in the 2002 of 616 participants. 2010, the year it was bought, witnessed another jump to 706 participants. In 2013, there were 1028 registered participants. To enter the race costs $\$ 285$, with no previous ultramarathon experience necessary. Literally any adult can sign up for the Leadville 100 (and minors with parental consent).

The 2013 edition of Leadville has been highlighted as what is becoming wrong about ultrarunning, an event that is increasingly attracting the inexperienced who are merely seeking to do an ultra to say they did an ultra (or what can be called "buckle listers5" in reference to the belt buckle one can get upon finishing under a certain time). The large number of runners, seemingly little organization, crews and traffic jams, pacers, lack of aid station supplies, frustration with race director responsiveness to complaints and problems, and the presence of a multi-million dollar corporate sponsor have made the Leadville 100 emblematic for the corporatization of ultrarunning6. This led to many blog posts and on-line discussions in public forums regarding people's positive and negative experience at Leadville.

One blogger wrote that "From the throngs of people, cars, and racers, to the gross disorganization and ubiquitous stench of port-a-johns, this felt more like a dirty, overcrowded music festival than a prestigious trail race - the epic scenery of the Sawatch eclipsed by traffic jams, cranky volunteers, and a constant plume of dust from too many tires on the dirt roads" (Misiak 2013). Another blogger attributes the problems to Lifetime's corporate identity, and that "It doesn't make sense for a chain of gyms to get involved in ultrarunning and try to run one of the world's most storied 100 milers, especially when a small town's very livelihood is at stake” (Hornsby 2013). Ultrarunner Rod Bien (2013), who has many ultra wins and was there to pace a friend, described one scene:

I was pacing from Fish Hatchery (mile 75ish) on the way back. My runner had fallen off pace and was closer to the back of the pack at this point. When I arrived to Fish Hatchery in the early morning hours of Sunday, it literally felt like a scene from Apocalypse now. There seemed to be no one really having any control of the aid station. Yes, the runners were chipped but they were coming and going without any real notice or checking in or out. The entire aid station was littered with trash. Garbage cans had long since overflowed and folks simply were putting garbage on the ground. It was a very bizarre scene.

This is not meant to give the impression that this was everyone's experience, and that everyone who attended and participated in Leadville had the same view. There are those who would profess that they had no (or few) problems with the race7. Furthermore, there is a general sentiment that people want the race to go well. In this way, the race has the feel of a local business, the community store that while privately owned still feels like it is part of the fabric of all who live there. No one in the community may profit financially from the business, but the livelihood of the business says something about the community's vitality, and the relationships built over time between residents and workers creates an intimate and emotional relationship. For many, it feels like the local store has been bought out by a chain.

The outcry was enough that the Hardrock 100 removed Leadville as a qualifier for their event, stating that "the 2013 Leadville 100 ignored other traits of importance to [Hardrock]: environmental responsibility, support of the hosting community, and having a positive impact on the health of our sport", and thus would not be included as a qualifying invent for 2015 and beyond (http://hardrock100.com/hardrock-qualify.php). Stan Jensen, who runs the website run100s.com, which serves as a vast repository of information and data on the history of ultramarathon events, posted on November 11, 2013, “Sorry, but I'm removing the Leadville 100 from my web site. They're no longer a part of the sport of ultrarunning, but simply a business venture" (run100s.com/whatsnew.htm). Thus, you cannot find any mention or reference to the Leadville 100 on his site.

The Leadville 100 recently broke silence on the issue, despite various requests for commentary, to provide "Improvements Planned for 2014 Leadville Trail 100 Run." This is to include reduced participation numbers, changes to aid station access, better trash management, more staff and volunteers, all to demonstrate that they are "committed to contribute positively to the future of Ultra running." It should also be noted that an economic impact study conducted by researchers at Colorado Mountain College (located in Leadville) stated that the race 
series contributes $\$ 15$ million to the local economy. This was determined through surveying participants, and their spending habits associated with the various races and training activities that take place in Leadville. It also added in additional monies earned by local employees during race activities. Without getting into the specifics of how much is made, and how accurate these numbers are, it is clear from anyone who has been to Leadville that these events do bring in money to the community. If that is the goal, then that is accomplished, and likely will continue to be accomplished as more ultrarunners and mountain bikers get into these sports. However, if the goal is to maintain the spirit of these events, and the sports they represent, then there is a growing concern of whether it is possible in this model of race-for-profit and corporate sponsorship. Finally, as more sponsorship and attention is given to ultrarunning, there is the concern of whether more and more races will go the way of Leadville, and whether the price of popularity is worth the cost of culture.

\section{| Conclusions: The Trail Ahead}

By your endurance you will gain your souls

(Luke 21:19 New Revised Standard Version)

In Ancient Greece, the concept of agon related to contest, competition, struggle and challenge, especially pertaining to the development of the Olympic Games. It not only relates to an external struggle against an opponent, but an inward struggle of the soul. Within struggle there is hope that through perseverance, that by enduring external and internal challenges, one will come through transformed with a renewed sense of self and a removal of limitations. Endurance is the thing, and learning to endure is the skill needed to be acquired. Likewise the quote above taken from Luke was uttered as a foretelling of the persecution that the Apostles would encounter through their following of Jesus, and that by enduring that persecution they would achieve an eternal life. As a metaphor, one can see direct application to the world of ultrarunning, where struggle and endurance is viewed as a gateway to self-discovery that is accomplished by going into a realm that today's modern society is constructed to actively avoid. Within ultra comes a kind of purity of existence in that moment, where all of the things that can plague us every day are stripped away and focus is turned toward just keeping moving forward. In recalling her participation in the Iditarod mountain bike race, Jill Homer (2008:Ch.1) relates, "What we seek is the truth. Not the truth shaped by human knowledge, but the Truth: harsh, unwritten and startingly real."

To run is to engage in one of the simplest human activities. Shortly after crawling and walking comes running. The freedom of moving 'fast' equates to the ability to cover greater distance, expanding range and opportunities. More research is examining how human beings evolved as long-distance runners. "Considering all the evidence together, it is reasonable to hypothesize that Homo evolved to travel long distances by both walking and running" (Bramble and Lieberman 2004:351). Today, as Bernd Heinrich (2009:131) observes, "Running is not just biological destiny. Rather it is a biological capacity that is now largely a cultural phenomenon." The question then becomes what kind of culture is it, and how is it changing. What was primal has become popular, and what is popular will eventually become marketed. It is in this final step that ultrarunning is finding itself today, as the point between what it has been and is becoming.

On the question about commodification and standardization of ultrarunning, one ultrarunning participant (and commentator) gave the following assessment on his blog: "Competitive Running will continue toward homogeneity. As sponsors invest more and more money into athletes and races, they will expect those athletes and races to produce more and more money. This will be accomplished not by bringing the average person onto the trail, but by bringing trail running into the average person's living room via television and internet" (Vaughan, 2013). Is the taming of ultra for the "average person" something needed, desired, or necessary? The question still remains whether this is something that ultrarunners want to see happen. More specifically, we could ask if there are now different parts of the ultrarunning community that want different outcomes, and in the process is a bifurcation of ultrarunning beginning.

At the same time, this concern might be much ado about nothing. For every high profile event you can likely find more community oriented 'Fat Ass' events, where no awards are given, no places won, timing may not be kept, aid tables are pot lucks, and entry fees non-existent or minimal. Graubin (2008:2) explains, "Fat Ass events, completely 
informal and often non-competitive runs, have become a fun alternative to the intense environments of the bigtime, high-demand races." The 'old school' ultra experience is still there to be had, and not likely to go away. For instance, a new race called the Twin States $50 \mathrm{~m}$ has just emerged, for which there is no entry fee, no aid stations, and registration involves basically an RSVP to the race director. Unlike other Fat Ass races, however, there will be awards, which include, "Top overall male and female will win one item from my pantry, or some other random object. Things in my pantry include canned rabbit, mushrooms, tomato sauce, creamed corn or any variety of things8." As elite ultramarathoner Anton Krupicka states, "I think the sport is big enough to accommodate both kids of races: those with large fields, media, prize money, and a focus on the sharp end and those that are more low-key and grassroots with no fanfare" (Seiss 2012).

The question could be asked, then, why the fuss? Why should there be concern over the growth of the sport in one direction when it seems likely that it can retain its roots? Part of this may lie in those fearful that ultra is becoming the thing that it originally rejected. Is it possible to find yourself in the midst of adversity when much is done to ensure your success? If you are not allowed to find your limits, how can you go past them? Ultrarunners might look toward mountain biking, which went from a fringe outsider oriented activity in the woods, and turned into looped courses for better viewing, televising, marketing, and eventually inclusion in the Olympics. Making ultra more accessible is not only a concern about field sizes, but also removing the essence of what makes it important as a way to explore personal limits (or struggle) and then find what one is capable of.

The Barkley Marathons is one of the hardest ultramarathons in the world. Competitors must finish the 100 mile event (the course is likely longer than this) in 60 hours. Held in various versions since 1986, the 100 miler course (5 loops) came into being in 1995. Since that time, only 14 people have successfully completed the course before the cutoff. Race Director and race creator Gary Cantrell said, "The Barkley is a problem. All the other big races are set up for you to succeed. The Barkley is set up for your to fail" (Seminara 2013). There are no aid stations or marked trail. It is difficult to find out how to enter the race, and it costs $\$ 1.61$ for first timers to enter. Only around 40 people can participate a year due to park rules. There have been attempts to pay up to $\$ 1,000$ to enter, and they have been turned down.

While undoubtedly people would like to finish, and there are the very few that do, finishing is not always the point. Multiple time Ironman World Champion Chrissie Wellington in her autobiography states, "You will remain the same person before, during and after the race, so the result, however important, will not define you. The journey is what matters" (Ch.10). The journey does not begin at the starting line, but in the course of training, immersing oneself in the day-to-day struggle to even approach the starting line with a sense of preparedness. Or, as ultrarunning great Scott Jurek (2012:Ch.12) has found, "The point was living with grace, decency, and attention to the world, and breaking free of the artificial constructs in your own life. I know all that now. I sensed it then."

It often is in struggle that people can unite for a common purpose, allowing difference to be shed for a shared goal and experience. Fiona Wilson in commenting on the nature of ultrarunners states, “There's a camaraderie from knowing you're all going through the same thing. When you spend six hours running with someone, it's an intense relationship and I've ended up revealing quite intimate details to complete strangers" (Carlyle 201). As was shown in the survey results, community and identity are important elements of the ultrarunning culture. As author Bill McKibben (2010:45) recalled this most memorable piece of advice in his own foray into cross-country ski racing, “At every endurance event, there comes a time when you'll say, 'What the fuck am I doing here?' And you'll say, 'This is what I do.".

In "This is what I do" lies "This is who I am", and more generally "This is who we all are who participate in this same activity." It is this part that raises concern as the growth and commercialization stand to change what the sport is to those who take part, and what the sport appears to be to those on the outside looking in. Ellie Greenwood, a professional ultrarunner, provides the following on the issue of change, "Let's support the competitive element in ultrarunning by allowing competitive runners to make a good income, but let's not close our eyes to the challenges and changes this may cause to our sport" (Greenwood 2012). The concern now is whether the growth and increased commercialization of the sport possess a threat to the spirit of the trail, and the ethos that became established in ultra.

The goal of this paper was to provide a deeper understanding on ultramarathoning participation, identity, culture and growth. As ultrarunning continues to grow in terms of race size and market share, more will be needed to be done to examine whether it can achieve a model of economic, environmental, and cultural sustainability. There is much to be written on ultramarathon, and more to be explored. It is in many ways a fundamentally simple activity involving nothing more than (typically) a trail and a desire to see how far one can go. It would seem that ultimately 
people want to see that simplicity retained. The question then becomes whether simplicity can be achieved with popularity and profitability. That question has yet to be decided in the world of ultramarathoning. As it unfolds, it will provide an interesting avenue to explore how cultural change and resistance function in a world where the certainty of the finish line is almost always in question and the experience of the moment all that can be guaranteed.

\section{Endnotes}

1. For a recounting of this event, see the movie Unbreakable: The Western States 100 (2011).

2. Elevation Trail, elevationtrail.com

3. This acronym was chosen intentionally. One aspect of ultrarunning culture is the irreverence with which bodily functions are treated. Vomiting can be seen as a race-day strategy to help with completion of the event. Discussions of urination and defecation are commonplace among and between men and women. During longer distance ultras, it is not uncommon for people to change clothes in view of others. As one runner said to another runner as she urinated off to the side of the trail during the Leadville 100 (and in view of one of the authors who was 'pacing' another runner), "There is no shame in ultrarunning."

4. The concept of what defines an "elite" runner is a very tricky one for which there is no definite answer. A 'professional' runner might be defined as a person who makes their living from running. This is very rare in ultrarunning, with perhaps only a few exceptions. The use of the word 'elite' is referring to those who are in positions to win prize money and finish at the front and/or win races. They are acknowledged by others in the field as being the top of ultra performance, and thus given that title of 'elite.' It might be the case that they themselves would not call themselves elite, or feel uncomfortable when the term was applied to them. Nevertheless, their performances and often sponsorships puts them in a different category from other ultrarunners as it pertains to the importance of compensation for ultrarunning.

5. This is a play on the term "bucket lister" which refers to people who have a list of things they want to achieve. When something is achieved, it is crossed off the list in order to move onto the next thing.

6. The primary author was part of a podcast on Elevation Trail discussing the corporatization of ultra and the Leadville 100, as the podcast host was a participant in the event as well. http://elevationtrail. wordpress.com/2013/08/19/leadville-100-andcorporate-manhandling-of-ultrarunning/

7. An online search on the 2013 Leadville 100 run would yield more points for consideration. For instance, perusing the 166 comments at the irunfar. com discussion of the race and results would give more indication of the sentiments that have been expressed. http://www.irunfar.com/2013/08/2013-leadville-100mile-run-results.html

8. https://sites.google.com/site/twinstate50/home

\section{References}

Active.com (2011, March 14) Active Network tracks surge in U.S. running event participation. Retrieved from http://www. activenetwork.com/about-us/press-room/press-releases/2011press-releases/active-network-tracks-surge-in-US-runningevent-participation.htm

Agger, Ben. 2010. Body Problems: Running and Living Long in a Fast-Food Society [Kindle Version]. Routledge. New York, NY.

Bien, Rod. 2013. Leadville loses its soul. August 21st. Retrieved November 14, 2013. http://rodbien.blogspot.com/2013/08/ leadville-loses-its-soul.html.
Burgunder, R. (2010, May 18) Trail running: racing toward the top in popularity. Retrieved from http://www.sportsnetworker.com/2010/05/18/ trail-running-racing-towards-the-top-in-popularity/

Carlyle, R. (2011, March 3) Could you run an ultra-marathon? The Telegraph. Retrieved from http://www.telegraph.co.uk/ active/8359417/Could-you-run-an-ultra-marathon.html

Chase, Laura Frances. 2008. Running big: clydesdale runners and technologies of the body. Sociology of Sport Journal, 25: 130-147. 
Cooper, Pamela L. 1992. The "visible hand" on the footrace: Fred Lebow and the marketing of the marathon. Journal of Sport History, 19(3):244-256.

Dzierzak, L. (2009) A different trail to climb: the competitive landscape in the trail running market is changing. Performance Sports Retailer, 41(6), 1, 8-11.

Erskine, C. (2013, May 24) Shannon-Farar-Griefer hears the call of the wild Badwater race. Los Angeles Times. Retrieved from http://www.latimes.com/sports/la-sperskine-20130524,0,3088048.column

Graubins, G. (2008) Growing pains. Trail Runner Magazine, December. Retrieved from http://www.trailrunnermag.com/ races/3-ultrarunning/696-growing-pains

Greenwood, E. (2012, September 18) The politics of prize money. iRunFar.com. Retrieved from http://www.irunfar. com/2012/09/the-politics-of-prize-money.html

Greenwood, S. (2012, September 7) The rise of the ultramarathon. The Guardian. Retrieved from www.guardian.co.uk/ travel/2012/sep/07/ultra-marathons-running.

Hanold, Maylon T. 2010. Beyond the marathon: (de)construction of female ultrarunning bodies. Sociology of Sport Journal, 27:160-177.

Heinrich, Bernd. 2009. Why We Run: A Natural History [Kindle Version]. HarperCollins e-books. New York, NY.

Hoffman, M.D. \& Fogard, K. (2012) Demographic characteristics of 161-km ultramarathon runners. Research in Sports Medicine, 20(1), 59-69. doi: 10.1080/15438627.2012.634707

Hoffman, Martin D. and Eswar Krishnan. 2013. Exercise behavior of ultramarathon runners: baseline findings from the ULTRA study. Journal of Strength and Conditioning Research, 27(11):2939-2945.

Hoffman, M.D., Ong, J.C. \& Wang, G. (2011) Historical analysis of participation in $161 \mathrm{~km}$ ultramarathons in North America. The International Journal of the History of Sport, 27(11), 18771891. doi: 10.1080/09523367.2010.494385

Hoffman, M.D. \& Wegelin, J.A. (2009) The Western States 100-mile Endurance Run: participation and performance trends. Medicine and Science in Sports Exercise, 41(12), 21912198. doi: 10.1249/MSS.0b013e3181a8d553

Homer, Jill. 2008. Ghost Trails: Journey through a Lifetime [Kindle Version]. Artic Glass Press. www.articglasspress.net.

Hornsby, Wyatt. 2013. What's really wrong with Leadville. August 31 st. Retrieved November 14, 2013. http://nolimitsever. blogspot.com/2013/08/whats-really-wrong-with-leadville.html

Johnson, K. (2005, March 16) A runner's quest for the ache of life. New York Times. Retrieved from http://www.nytimes. com/2005/03/16/books/16runn.html

Jones-Wilkins, Andy. 2011. Ultra prize money doesn't change why they run. December 1st. Retrieved November 14, 2013. http:// www.irunfar.com/2011/12/ultra-prize-money-doesnt-changewhy-they-run.html.
Jurek, Scott. 2012. Eat and Run: My Unlikely Rise to Ultramarathon Greatness [Kindle Version]. Houghton Mifflin Harcourt, New York, NY.

Karnazes, D. (2005) Ultramarathon man: confessions of an all-night runner. New York: Penguin Books.

Kim, Jonathan H. et al. 2012. Cardiac arrest during longdistance running races. The New England Journal of Medicine, 366(2):130-40.

Lacroix, J. (2012, March 5) Ultrarunning growth. Retrieved from http://sherpajohn.blogspot.com/2012/03/ultrarunninggrowth.html.

McDougall, C. (2009) Born to run: a hidden tribe, superathletes, and the greatest race the world has never seen. New York: Knopf.

McKibben, Bill. 2010. Long Distance: Testing the Limits of Body and Spirit in a Year of Living Strenuously [Kindle Version]. Rodale Press. Emmaus, PA.

Mesure, S. (2010, September 5) Ultra-running: a marathon is no longer good enough. The Independent. Retrieved from http:// www.independent.co.uk/sport/general/others/ultrarunninga-marathon-is-no-longer-good-enough-2070834.html.

Misiak, Amanda. 2013. Why the Leadville Trail 100 felt like Lollapaqlooza - is Lifetime Fitness a friend or foe? August 27th. Retrieved November 14, 2013. http://andrewskurka. com/2013/why-the-leadville-trail-100-felt-like-lollapalooza/

Mondovics, Tamas. 2013. Ultramarathon runner ready to defend world championship title, seeks community support. Osprey Observer, April 1st. Retrieved November 14, 2013. http:// www.ospreyobserver.com/2013/04/ultramarathon-runnerready-to-defend-world-championship-title-seeks-communitysupport/

Morelock, John. 2013. Run Gently Out There: Trials, Trails, and Tribulations of Running Ultramarathons.

Murray, Andrew and Ricardo JS Costa. 2012. Born to run. Studying the limits of human performance. BMC Medicine, 10:76-78.

Nowak, Pawel F. 2010. Ultra distance running in view of health and amateur sport. Human Movement, 11(1): 37-41.

Palmer, L. (2013, May 28) What are extreme runners thinking? Slate. Retrieved from http://www.slate.com/articles/health_ and_science/superman/2013/05/ultramarathon_runner_ scott_jurek_extreme_athletes_determination_pain_and.html

Roes, Geoff. 2012. Young money: effects of the new big money on ultras. August 15th. Retrieved November 14, 2013. http:// www.irunfar.com/2012/08/young-money-effects-of-the-newbig-money-ultras.html.

Running Insight (2012) Happy trails: brands upbeat at busy outdoor retailer show. 3(15), 16-20. 
Sax, D. (2012, May 24) Chia seeds, Wall Street's stimulant of choice. Bloomberg Businessweek. Retrieved from http://www.businessweek.com/articles/2012-05-24/ chia-seeds-wall-streets-stimulant-of-choice

Seiss, D. (2012, May 23) Ultramarathon runners hope to raise their profile, and their prize money. Washington Post. Retrieved from http://articles.washingtonpost.com/2012-05-23/ sports/35458185_1_trail-races-runners-hope-marathons.

Seminara, Dave. 2013. Few know how to enter; fewer finish. New York Times, March 27th. Retrieved November 18, 2013. http://www.nytimes.com/2013/03/28/sports/the-barkleymarathons-few-know-how-to-enter-fewer-finish.html.

Solomon, Christopher. 2013. Becoming the all-terrain human. New York Times, March 20th. Retrieved March 20, 2013. http://www.nytimes.com/2013/03/24/magazine/creating-theall-terrain-human.html.

The Economist (2011, September 16) Running fads: bare facts. Retrieved from http://www.economist.com/node/21528957
Tulle, Emmanuelle. 2008. The ageing body and the ontology of ageing: athletic competence in later life. Body and Society, 14(3): 1-19.

U.S. Census (2011) PINC-03. Educational attainment--people 25 years old and over, by total money earnings in 2010 , work experience in 2010, age, race, Hispanic origin, and sex. Retrieved from http://www.census.gov/hhes/www/ cpstables/032011/perinc/new03_001.htm.

Vaughan, J. 2013. The future of ultrarunning. March 15th. Retrieved November 15, 2013. http://ultrapedestrian. blogspot.com/2013/03/the-future-of-ultrarunning.html

Vigneron, Peter. 2013. Win in Boston can add up in a hurry. April 11. http://espn.go.com/sports/endurance/story/_/ id/9156850/endurance-sports-how-much-does-winningmajor-marathon-pay. Retrieved November 13, 2013.

Wellington, Chrissie (2012) A Life without Limits: A World Champion's Journey [Kindle Version]. Center Street. London, UK. 